\title{
Técnicas de inteligencia artificial utilizadas en el procesamiento de imágenes y su aplicación en el análisis de pavimentos
}

\author{
$\triangle$ OSCAR JAVIER REYES-ORTIZ 1 \\ MARCEla MEJIA ${ }^{1}$ \\ JuAn SEbastián Useche-CASTELBLANCO ${ }^{1}$
}

\section{Resumen}

Debido al incremento en los costos de mantenimiento, rehabilitación y construcción de vías, estudiar las estructuras de pavimento para determinar su comportamiento y sus características mecánicas propias analizando la distribución y posición de sus partículas, se ha vuelto un campo de gran importancia en la ingeniería. Las nuevas herramientas de análisis buscan hacer este estudio más eficiente reduciendo su costo y tiempo de ejecución mediante el procesamiento digital de imágenes. El procesamiento digital tradicional está limitado en su sensibilidad ante perturbaciones externas que puedan modificar la imagen, por eso se han implementado diferentes técnicas de inteligencia artificial (IA) para optimizar los algoritmos. Este trabajo presenta una revisión de las diferentes aplicaciones de técnicas de IA recientes en el procesamiento de imágenes. Después se revisan los trabajos realizados específicamente con imágenes de pavimentos y se presentan posibles implementaciones futuras en este campo utilizando inteligencia artificial.

Palabras clave: Pavimentos, Inteligencia Artificial, Procesamiento Digital de Imágenes.

\section{Artificial Intelligence Techniques Used in the Processing of Images and Its Application in Pavement Analysis}

\section{Abstract}

Due to the increase in the costs of maintenance and construction road, the pavement structures study for determine the behavior and mechanical characteristics of material, analyzing the distribution of the particles, has become a field

1 Universidad Militar Nueva Granada, Bogotá, Colombia.

Autor de correspondencia: Reyes-Ortiz, O.J. (Oscar Javier): Universidad Militar Nueva Granada, Carrera 11 No 10180, Bogotá D.C., Colombia. Teléfono: 6500000 ext. 1291. Correo electrónico: oscar.reyes@unimilitar.edu.co
Historia del artículo:

Artículo recibido: 20-XI-2017/ Aprobado: 19-XII-2018

Disponible online: 3 de febrero de 2019

Discusión abierta hasta octubre de 2020 
of great importance in engineering. New analytical tools search to make this study more efficient with the reduce of its cost and execution time using image digital processing to extract the most useful photo features. Traditional digital processing is limited in its sensitivity to external disturbances that can modify the image, for this reason in recent years different techniques of artificial intelligence (AI) have been implemented to optimize the algorithms. This work presents a review of the different applications of recent AI techniques in image processing. Afterwards, the works made specifically with pavement images are reviewed and possible future implementations in this field are presented using artificial intelligence.

Keywords: Pavement, Artificial intelligence, image digital processing.

\section{Técnicas de inteligência artificial utilizadas no processamento de imagens e sua aplicação na análise de pavimentos}

\section{Resumo}

Devido ao aumento nos custos de manutenção e construção rodoviária, o estudo de estruturas de pavimentos para determinar o comportamento e as características mecânicas do material, analisando a distribuição das partículas, tornou-se um campo de grande importância em engenharia. Novas ferramentas analíticas buscam tornar esse estudo mais eficiente com a redução de seu custo e tempo de execução usando processamento digital de imagens para extrair os recursos de foto mais úteis. 0 processamento digital tradicional é limitado em sua sensibilidade a distúrbios externos que podem modificar a imagem, por isso, nos últimos anos, diferentes técnicas de inteligência artificial (IA) foram implementadas para otimizar os algoritmos. Este trabalho apresenta uma revisão das diferentes aplicações de técnicas recentes de IA no processamento de imagens. Posteriormente, os trabalhos feitos especificamente com imagens de pavimentos são revisados e possíveis implementações futuras neste campo são apresentadas usando inteligência artificial.

Palavras-chave: Pavimento, inteligência artificial, processamento digital de imagens

\section{Introducción}

En la actualidad la necesidad de implementar nuevas herramientas para el análisis y el estudio de la estructura de un pavimento es debido a que los costos de mantenimiento, reparación y construcción de vías se han venido incrementando (Babashamsi et al., 2016). El estudio de la estructura interna de una mezcla se puede realizar a partir de la obtención de la distribución de sus partículas en escalas micro, macro y mega; el determinarla permite asociar características mecánicas del material, como su capacidad de resistencia a cargas y condi- ciones medioambientales(Hu et al., 2016)(Knabben et al., 2016).

La investigación sobre las partículas de los materiales es importante en el campo de la ingeniería; para mejorar estos estudios se han desarrollado herramientas digitales usando imágenes, que permiten hacer inspección y obtención de información de una forma más precisa y sistemática para procesos que antes eran manuales. Existen dos tipos de métodos para el análisis de imágenes con partículas, el método directo que examina y segmenta un elemento buscando determinar formas o áreas individuales y el indirecto que analiza el conjunto completo (Bianconi et al., 2015)(Athertya \& Saravana Kumar, 2016). 
El estudio de imágenes en las mezclas asfálticas no solo se usa para examinar la granulometría determinando la orientación homogénea de sus componentes que va directamente relacionada con sus propiedades mecánicas, durabilidad, estabilidad entre otras (Han et al., 2016), sino que también se utiliza para detectar grietas en la estructura utilizando la segmentación de bordes y la manipulación del contraste de la imagen, obteniendo información sobre el tipo falla y elementos útiles para los estudios sobre pavimentos (Li et al., 2011).

El procesamiento digital de imágenes de acuerdo con Berrocal, Löfgren, Lundgren, Görander y Halldén (Berrocal et al., 2016) se centra en 3 etapas consecutivas como las son umbralización, limpieza y filtrado; según los autores cada una de estas desarrolla una serie de operaciones que permiten obtener la información requerida utilizando fotos RGB (Multicapa de 3 colores). La umbralización se realiza seleccionando los rangos de intensidad y manipulando los valores del histograma de cada capa, en la limpieza se obtienen formas definidas aplicándoles diferentes operaciones morfológicas para eliminar el ruido y los elementos innecesarios. Por otra parte el filtrado de características se realiza por medio del análisis espacial buscando encontrar objetos y geometrías (Michalska-Poggoga et al., 2016)(Bouchet et al., 2016).

Los métodos tradicionales presentan problemas de sensibilidad, por la interferencia de la luz en la captura, esto interfiere en la nitidez y contraste de la foto, en los años recientes se ha trabajado para tratar de mejorar estos sistemas con la implementación de técnicas de inteligencia artificial (IA) (Yu et al., 2016). Las técnicas IA más utilizadas en las últimas décadas para el procesamiento de imágenes según (Ali et al., 2015) son las redes neuronales, los sistemas difusos y los algoritmos evolutivos en donde se destacan los sistemas inmunes artificiales y la inteligencia de enjambre.

Trabajos recientes han usado la IA obteniendo buenos resultados como por ejemplo, las funciones de pertenencia gaussianas adaptativas de un sis- tema difuso presentado en (Cordeiro et al., 2016), en donde las reglas de parametrización se modificaban acorde a la segmentación de la imagen para determinar tumores en imágenes médicas, como resultado se obtuvo el contorno exacto del elemento en comparación a otros 5 autores. Por otro lado, el desarrollo de un sistema de clasificación de imágenes a partir de redes neuronales multicapa se puede observar en (Priya \& Srinivasan, 2016). En (Li et al., 2016)se utiliza un enjambre de abejas artificial como sistema de optimización en la recuperación de imágenes, como resultado se obtuvo un mejor porcentaje de recuperación en comparación a otros métodos ya que este permite una mejor redistribución de los puntos en función de sus vecinos más cercanos. Por otra parte los sistemas inmunes artificiales se utilizan como algoritmos de optimización de parámetros como se muestra en (Shang et al., 2014).

De lo anterior se observa como el procesamiento digital de imágenes ha mejorado al implementar diferentes técnicas de inteligencia artificial. Este trabajo presenta una revisión de los trabajos desarrollados últimamente en este campo, enfocándose en los sistemas difusos, las redes neuronales, la inteligencia de enjambre y los sistemas inmunes artificiales. Como complemento se resaltan los trabajos realizados con estas técnicas sobre las estructuras de pavimentos y se proponen futuras aplicaciones en esta área.

El desarrollo del trabajo se divide en 3 secciones, en la primera se muestran los trabajos realizados con cada técnica en el campo del procesamiento digital de imágenes. En la segunda se revisan las técnicas implementadas específicamente en pavimentos y se proponen posibles implementaciones para mejorar el procesamiento de imágenes en mezclas asfálticas y se finaliza con las conclusiones.

\section{Técnicas de inteligencia artificial en el procesamiento digital de imágenes}

A continuación se presentan las técnicas de inteligencia artificial más usadas en el procesamiento 
digital de imágenes, se muestran algunos trabajos desarrollados y los resultados obtenidos.

\subsection{Sistemas difusos}

Los sistemas difusos han tenido una gran aplicación en la ingeniería principalmente en las áreas de control y procesamiento digital de imágenes desde 1965 cuando Zadeh presentó la teoría de conjuntos difusos (Ngan, 2017). Helena, Miranda y Cezar argumentan en (Helena et al., 2015) que los conjuntos difusos se han usado en el trabajo con imágenes ya que no limitan numéricamente el desarrollo; esto es útil cuando se trabaja con imágenes debido a que sus características no se pueden delimitar de una forma exacta.

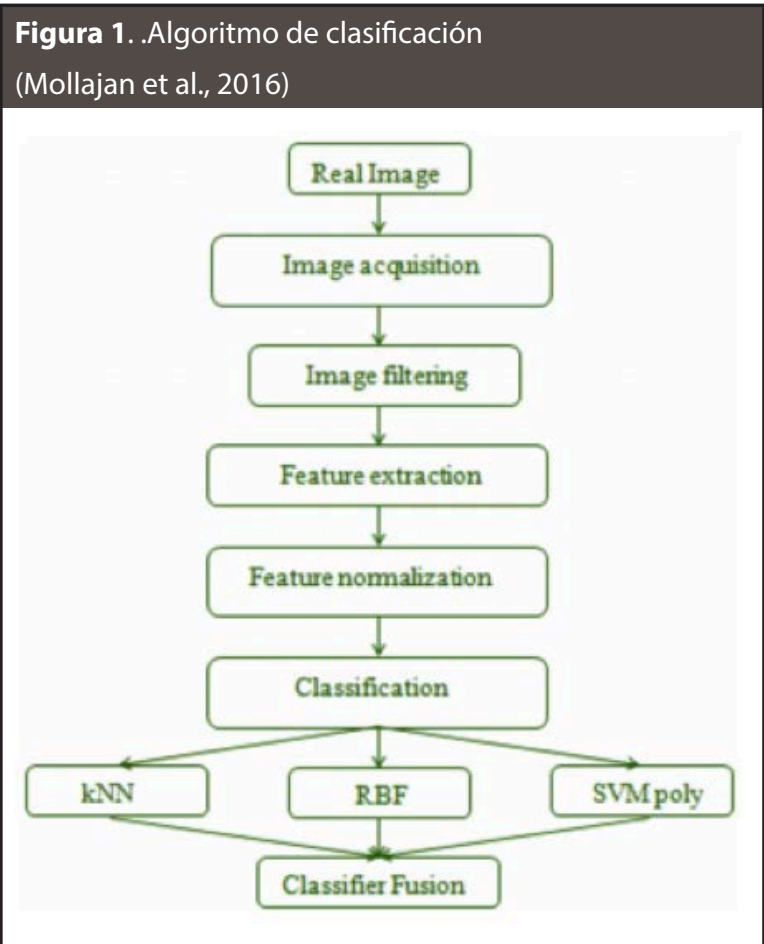

En los últimos años el procesamiento digital de imágenes utilizando lógica difusa se ha incrementado, a continuación se muestran algunas aplicaciones como la realizada por Amir Mollajan, Javad Ghiasi y Hossein Memarian (Mollajan et al., 2016) en donde el objetivo es desarrollar un algoritmo para la identificación de 5 tipos de poros diferentes en rocas carbonatadas. El algoritmo se de- sarrolla en 5 etapas como se observa en la Figura 1, las cuales son la filtración y segmentación, para separar por colores los poros que se encuentren; la extracción de características en donde aplicando máscaras se obtienen patrones característicos para su posterior clasificación; las últimas etapas consisten en aplicar 3 diferentes procesos para clasificar la muestra.

Con los resultados de cada método de extracción de características, se aplica un conjunto difuso el cual clasifica cada resultado, con el objetivo de determinar con mayor precisión el tipo de poro. En la Tabla 1 se ilustra la mejoría en el porcentaje de acierto usando el conjunto difuso en comparación al promedio de los métodos.

TABLA 1. COMPARACIÓN DEL MEJORAMIENTO DE LA CLASIFICACIÓN CON EL CONJUNTO DIFUSO

\begin{tabular}{|l|c|c|c|}
\multirow{2}{*}{\begin{tabular}{c}
\multirow{2}{*}{$\begin{array}{c}\text { Tipos de } \\
\text { poros }\end{array}$} \\
\cline { 2 - 4 }
\end{tabular}} & \multicolumn{3}{|c|}{ Detalles (\% del resultado) } \\
\hline Inter particle & 86.7 & 93.6 & +6.6 \\
\hline Intra particle & 88.9 & 95.2 & +6.3 \\
\hline Oomoldic & 100 & 100 & 0 \\
\hline Biomoldic & 100 & 100 & 0 \\
\hline Vuggy & 86.7 & 96.1 & +9.4 \\
\hline
\end{tabular}

Otra aplicación es la desarrollada por Imane Sebari y Dong-Chen (Sebari \& He 2013) quienes implementaron un conjunto difuso multisalida el cual extrae elementos urbanos como vegetación, edificios, calles y parqueaderos al aire libre de imágenes del satélite VHSR. El algoritmo de segmentación utilizado fue el propuesto por Sebari y He (Sebari \& He 2009) donde la única entrada es la imagen; los autores realizan esto utilizando los métodos de crecimiento por regiones y la segmentación por umbral. El conjunto difuso adquiere los datos de las segmentaciones y dependiendo de su valor se asigna a cada parte un atributo especial para poder situarlo en alguna categoría, en la Figura 2 los autores muestran el proceso completo de extracción de objetos. 
Figura 2. Extracción de objetos

(Sebari \& He 2013)

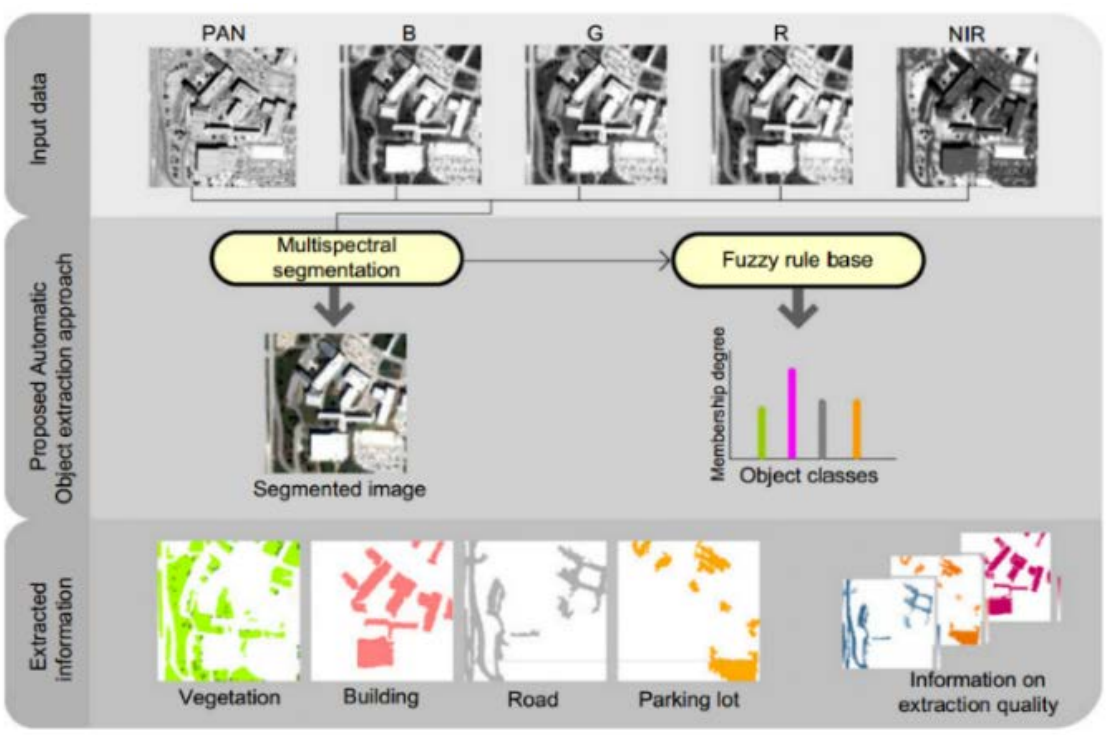

En la Tabla 2 se pueden ver los resultados del programa utilizando la Figura 3. Se obtuvo una calidad en la extracción de aproximadamente el 79\% en comparación al 81\% dela extracción realizada manualmente sobre el total del área de la imagen.

\section{TABLA 2. ERROR DE LA EXTRACCIÓN DE ELEMENTOS}

\begin{tabular}{c|c} 
Objetos & Porcentaje de aproximación (\%) \\
\hline Vegetación & 81 \\
\hline Agua & 97 \\
\hline Edificios & 81 \\
\hline Carreteras & 72 \\
\hline
\end{tabular}

\subsection{Redes neuronales artificialles}

Según Hugo, Albuquerque, Ripardo, Alexandria, y Ce (Hugo et al., 2009) el cerebro está constituido por neuronas que guardan y procesan una gran cantidad de información, por este motivo las redes neuronales artificiales buscan simular ese comportamiento del cerebro, permitiendo generar sistemas complejos creando una estructura donde se utilizan elementos simples (Mashaly \& Alazba 2016), a continuación se presentan dos tipos de redes; la multicapa que es la más utilizada y también las redes neuronales convolucionales, las cuales son especializadas para el trabajo con imágenes (Arjmandzadeh et al., 2017)(Huang et al., 2017).

Figura 3. (a) Imagen original (b) Objetos extraídos (c) mapa de referencia

(Sebari \& He, 2013)

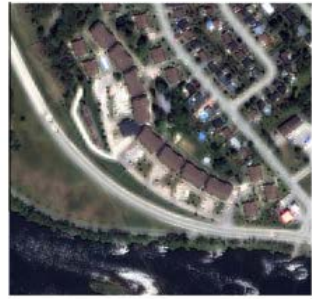

(a)

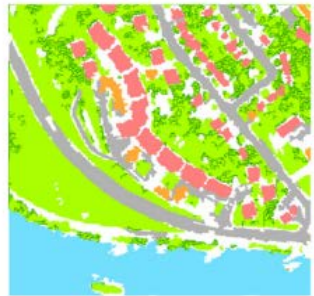

(b)

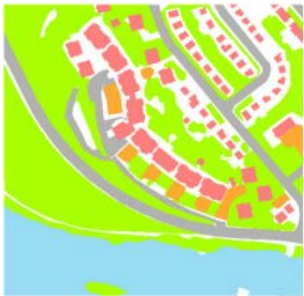

(c) 


\section{Figura 4. Estructura de la herramienta desarrollada}

(Mejía \& Alzate, 2015)
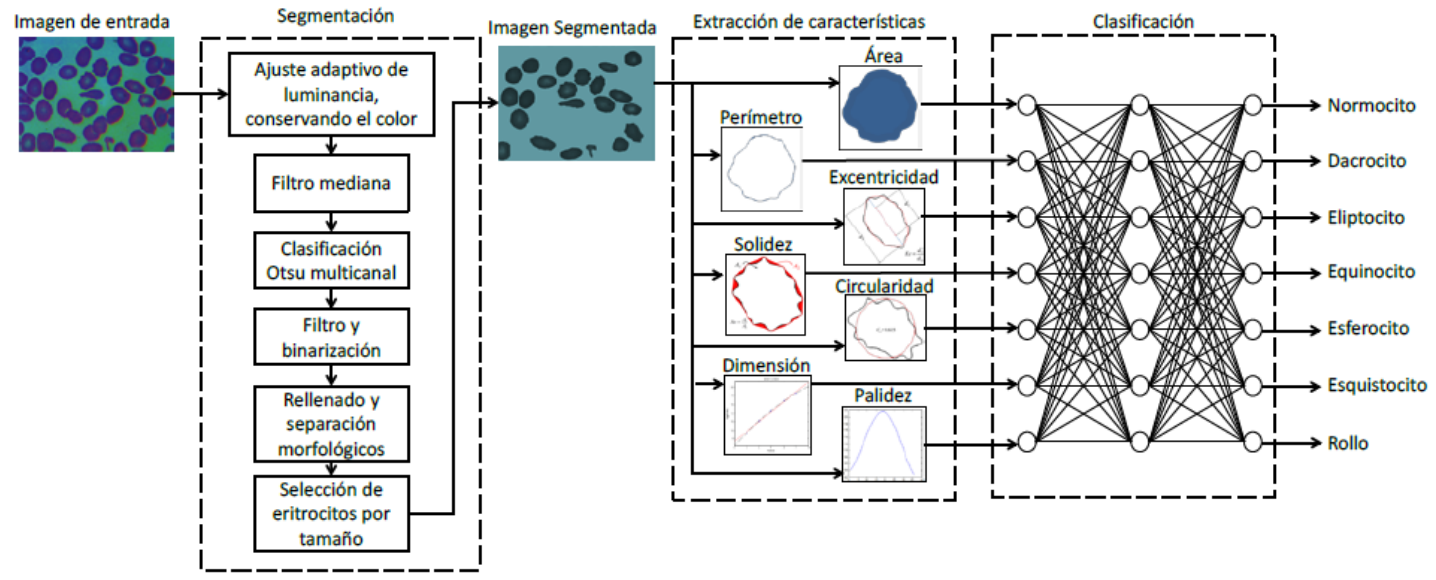

Figura 5. (a) y (a') son las trampas contra insectos, (b) y (b') son las regiones de interés, (c) y (c') grupos de interés, (d) y (d') insectos no objetivos. (Espinoza et al., 2016)

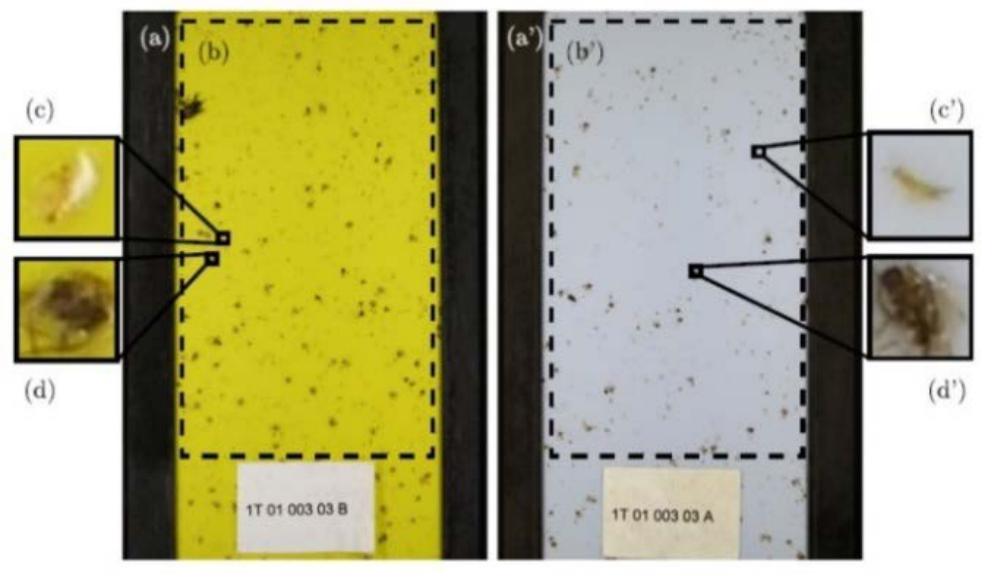

\subsubsection{Red neuronal multicapa}

La red neuronal multicapa o MPL (MultiLayer Perceptron) se basa en la unión de neuronas organizadas y distribuidas a lo largo de diferentes capas (Islam et al., 2014). Este tipo de redes sirven para copiar el comportamiento de cualquier sistema usando entradas y salidas conocidas, de esta forma es capaz de clasificar elementos o imitar el funcionamiento de una estructura (Hekayati \& Rahimpour, 2017).

Uno de los campos en el que más se utiliza este tipo de redes es medicina, los autores Marcela Mejía y Marco Alzate en (Mejía \& Alzate, 2015) desarro- llan una herramienta de apoyo diagnóstico para el examen de frotis de sangre periférica, en la cual con ayuda de una red neuronal buscan la clasificación de siete anormalidades en eritrocitos. La metodología consta de dos partes, un proceso de segmentación y uno de extracción; se usaron 23 imágenes, en las cuales fueron clasificados 265 eritrocitos de forma aislada por expertos. En la Figura 4 se muestra la metodología de trabajo.

Los resultados obtenidos muestran que la media entre los porcentajes de acierto de la red es superior al 97\% comparándolos con la clasificación 
realizada por el experto. De esta forma los autores presentan una herramienta para la clasificación de formas patologías de glóbulos rojos la cual supera los resultados de otros trabajos en el mismo campo.

Espinoza, Valera, Torres, López, y Molina (Espinoza et al., 2016) justifican el trabajo que se muestra a continuación por incremento en la demanda de la seguridad y calidad en la comida que diariamente consumen las personas, para esto en el campo han aparecido una serie de normativas en referencia al manejo de plagas, por este motivo se buscan nuevas técnicas de detección y prevención. En su trabajo los autores presentan una red neuronal en conjunto con un algoritmo de procesamiento digital de imágenes para identificar las plagas más agresivas en cultivos de tomate de las granjas del sur de España las cuales son la mosca blanca y la pergande. El proceso consta de un algoritmo de identificación que por medio del procesamiento digital de imágenes extrae la región de estudio, segmenta el objeto y posteriormente una red neuronal clasifica el insecto dentro o fuera de los grupos de interés. En la Figura 5 se observan las muestras que utilizaron.

Los resultados que se observan en la Tabla 3 muestran una precisión del $96 \%$ en la detección de moscas blancas y del $92 \%$ para pergande, una aproximación bastante elevada para un trabajo que actual- mente realiza una persona y su efectividad depende de su experiencia en el reconocimiento de insectos.

TABLA 3. RESULTADOS DE LA CLASIFICACIÓN DE PLAGAS

\begin{tabular}{|c|c|c} 
& Mosca blanca & Pergande \\
\hline Valor observado & 3266 & 1778 \\
\hline $\begin{array}{c}\text { Pronóstico de } \\
\text { detección }\end{array}$ & 3232 & 1857 \\
\hline $\begin{array}{c}\text { Detectados } \\
\text { correctamente }\end{array}$ & 3102 & 1707 \\
\hline $\begin{array}{c}\text { Detectados } \\
\text { incorrectamente }\end{array}$ & 130 & 71 \\
\hline Precisión (\%) & 96 & 92 \\
\hline
\end{tabular}

\subsubsection{Red neuronal convolucional}

Las redes neuronales convolucionales (CNNs) se han usado últimamente en tareas de análisis de imágenes, sobretodo destacando su uso en los procedimientos de clasificación y reconocimiento (Zhang et al., 2017). Este modelo de red se ha desarrollado inspirado en el sistema de aprendizaje biológico. Según W. Zhang, Qu, Ma, Guan, y Huang (Zhang et al., 2016) extraer las características propias de un elemento que lo diferencian de otros es un proceso que realizan los seres humanos con la vista y que las CNNs tratan de emular. Para el trabajo con imágenes se utilizan este tipo de redes porque permiten el manejo de grandes estructuras de datos (Ferrari et al., 2017).

\section{Figura 6. Esquema de funcionamiento de la CNN}

\section{(Yangyan et al., 2015)}

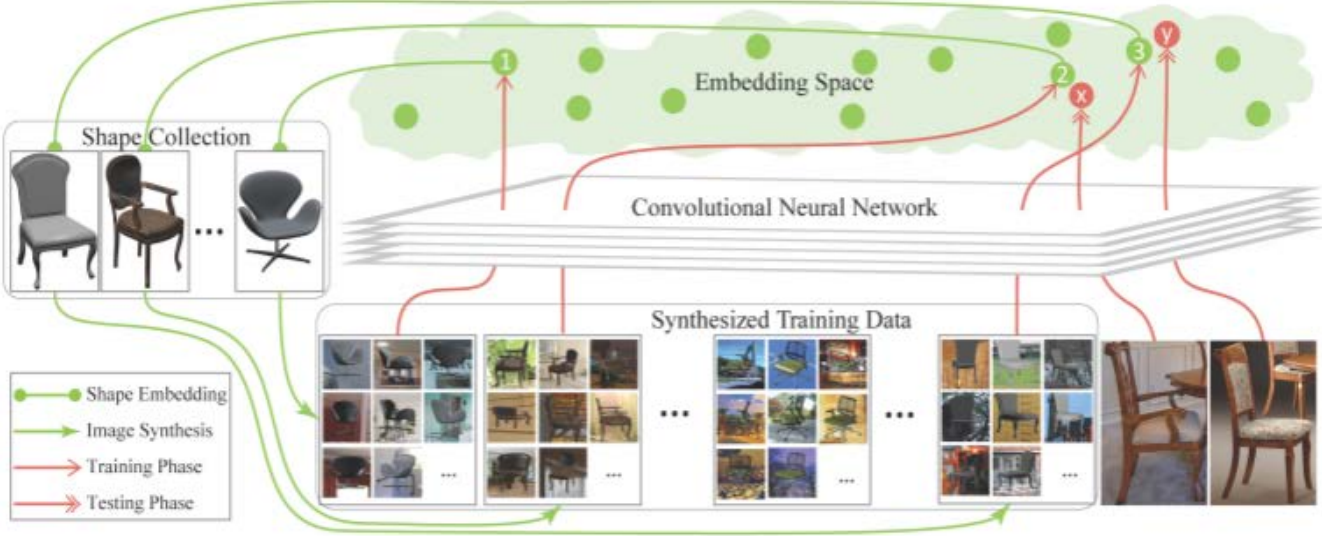


Dentro de las aplicaciones realizadas se encuentra el trabajo de Yangyan, Ruizhongtai, Fish, Cohen y Guibas (Yangyan et al., 2015) que surge frente a la necesidad de seguir mejorando los algoritmos computacionales en función al tema de visión de máquina y sobre todo en el reconocimiento de objetos, por eso se presenta el desarrollo de una CNN que integra un gran número de imágenes y de modelos CAD, la cual es capaz de por medio de una imagen reconstruir un ambiente 3D.

En la Figura 6 se puede observar la estructura en donde se ilustra el espacio creado que relaciona un objeto 3D con diferentes imágenes patrón, las cuales van a ser comparadas con las fotos de muestra para poder asociarla y ubicarla con un porcentaje de acierto a alguno de los grupos creados.

Los resultados muestran que el modelo desarrollado tiene una respuesta de detección más rápida y acertada con una cantidad menor de fotos. En la imagen 7 se observa una respuesta de la red en donde entrega el espacio 3D de la foto analizada.

Por otra parte J .Tan, R. Acharya, S. Bhandary y K. Chua en (Tan et al., 2017) presentan un algoritmo de segmentación de imágenes oculares en donde se buscan identificar los vasos vasculares, la fóvea, el disco óptico y el fondo del ojo utilizando una red neuronal convolucional. En la Figura 8 se observan las regiones de interés que se desean detectar; la red neuronal consta de 3 canales, esto se realiza para disminuir el costo computacional del programa usando imágenes más pequeñas pero brindándole más información a la red al tener una entrada múltiple. Para el entrenamiento se utiliza el algoritmo de back-propagation.

Los resultados en comparación a otros trabajos se muestran en la Tabla 4, en donde se manejan 2 indicadores, el primero de sensibilidad que representa el porcentaje de pixeles identificados correctamente de la parte objetivo y la especificidad que es el porcentaje de pixeles que no fueron asignados a un grupo incorrecto.

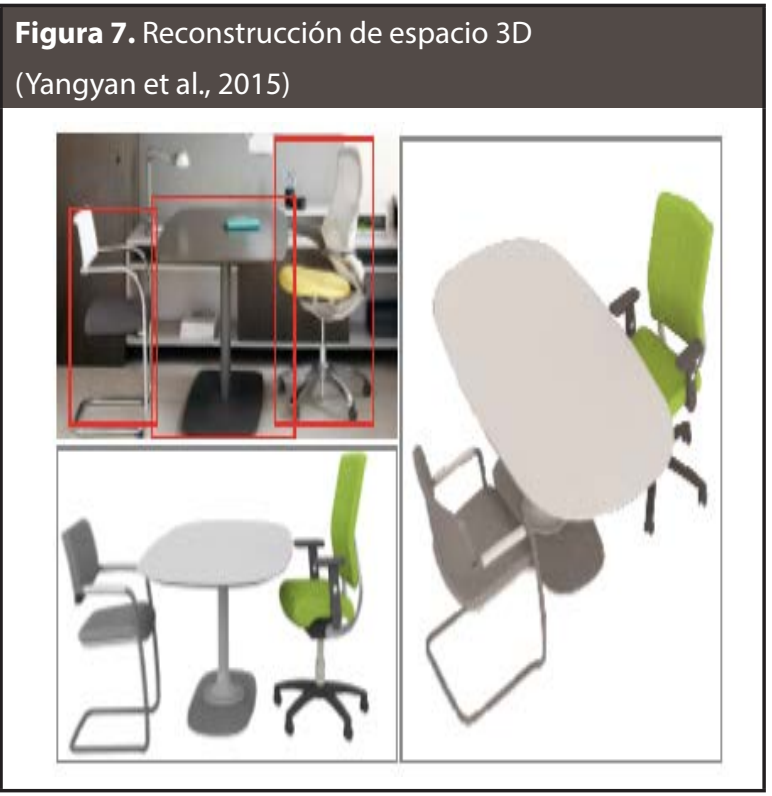

TABLA 4. COMPARACIÓN DE RESULTADOS (TAN ET AL., 2017)

\begin{tabular}{|l|c|c|c|c|c|c|c|}
\multirow{2}{*}{ Trabajos } & \multirow{2}{*}{ Año } & \multicolumn{2}{c|}{ Vasos vasculares } & \multicolumn{2}{c|}{ Fóvea } & \multicolumn{2}{c|}{ Disco óptico } \\
\cline { 3 - 8 } & & Sensibilidad & Especificidad & Sensibilidad & Especificidad & Sensibilidad & Especificidad \\
\hline \multicolumn{1}{c|}{ CNN } & 2017 & 0.7537 & 0.9694 & 0.8853 & 0.9914 & 0.8790 & 0.9927 \\
\hline 2nd observer & 2017 & 0.7796 & 0.9717 & - & - & - & - \\
\hline Zhu et al. & 2016 & 0.7140 & 0.9868 & - & - & - & - \\
\hline Wang et al. & 2014 & 0.8104 & 0.9791 & - & - & - & - \\
\hline Welfer et al. & 2013 & - & - & - & - & 0.8354 & 0.9981 \\
\hline Stapor et al. & 2004 & - & - & - & - & 0.7368 & 0.9920 \\
\hline Kande et al. & 2008 & - & - & - & - & 0.6999 & 0.9888 \\
\hline
\end{tabular}


Figura 8. Regiones de interés. (Tan et al., 2017)
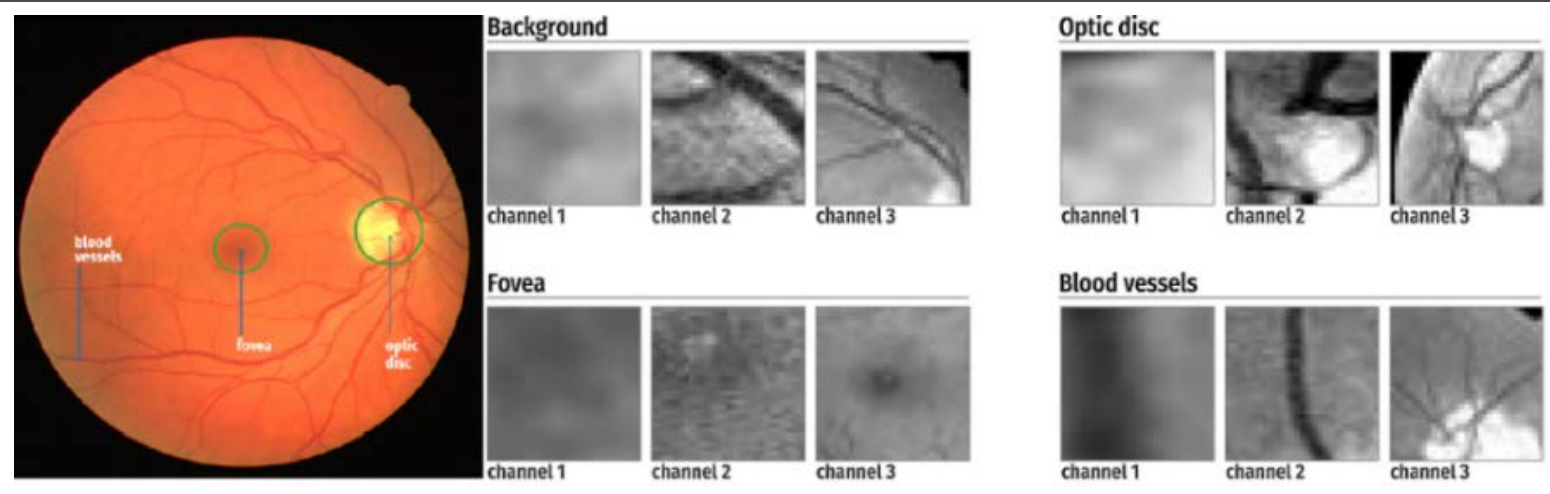

Blood vessels

\subsection{Inteligencia de enjambre}

La inteligencia de enjambre según Apostolidis y Hadjileontiadis (Apostolidis \& Hadjileontiadis, 2017) hace referencia a darle a un sistema artificial propiedades inspiradas en grupos de animales que realizan acciones conjuntas para cumplir con una tarea específica. Muchos modelos se han implementado con base al funcionamiento de grupos de trabajo colectivo entre los que encuentran las colonias de hormigas, abejas, crecimiento bacterial, grupos de aves, peces y el pastoreo de animales (Mavrovouniotis et al., 2017). De acuerdo con Kumar y Mishra(Kumar \& Mishra, 2017) la colonia de abejas es uno de los sistemas de enjambre más utilizados para tareas de optimización y análisis de imágenes por su fácil implementación.
La segmentación de imágenes es el proceso mediante el cual se divide una imagen en múltiples segmentos de pixeles, según Ankita Bose y Kalyani Mali (Bose \& Mali, 2016) esto es típicamente usado para localizar elementos en una imagen y por eso los autores presentan un modelo FABC, el cual es una combinación entre una colonia de abejas con funciones de pertenecía difusas. El algoritmo de trabajo se basa en la colonia de abejas buscando en la imagen los diferentes grupos de intensidad, en base a estos los valores de las funciones de pertenencia del conjunto difuso se van modificando. Una vez el algoritmo deje de detectar cambios de intensidad, los pixeles de la foto serán asociados al grupo más cercano. En la Figura 9 se observa el resultado con una segmentación a color y con otra en escala de grises.

Figura 9. (a)Imagen original, segmentación por (b) FABC, (c) PSO, (d) GA, (e) EM

(Bose \& Mali, 2016)

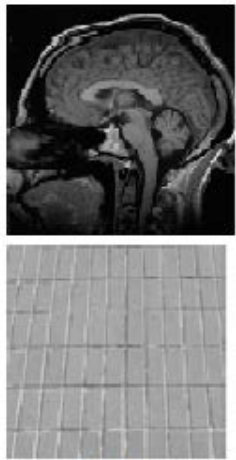

(a)
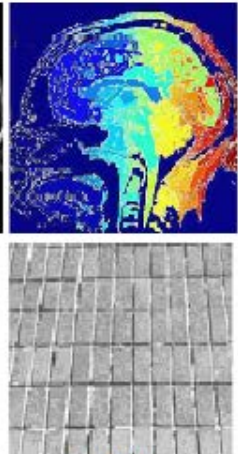

(b)
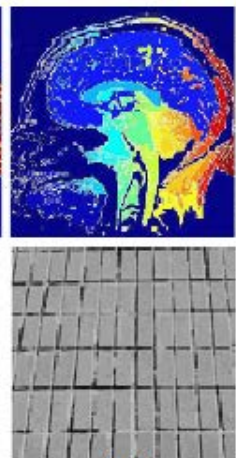

(c)

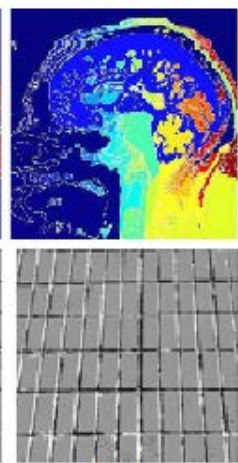

(d)
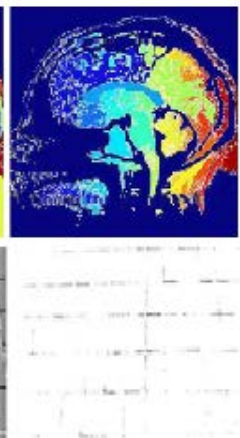

(e) 
En la figura anterior se puede apreciar como el algoritmo desarrollado (FABC) puede diferenciar más regiones tanto en color como en escala de grises, en comparación a los métodos de optimización por enjambre de partículas PSO, algoritmos genéticos GA y expectativa de maximización EM.

Por otra parte los autores Salima Nebti y Abdallah Boukerram (Nebti \& Boukerram, 2017) dicen que los sistemas de seguridad para el control de acceso son vulnerables y poco seguros, por eso se ha venido trabajando con biometría intentando mejorarlos, por este motivo proponen dos modelos diferentes de reconocimiento facial, uno basado en un enjambre de abejas y el otro un enjambre de partículas basado en un árbol de decisión, el valor de acierto en la clasificación para los dos se compara con un sistema de clasificación difuso (FSVM). El algoritmo utilizado se basa en tres partes, la detección del rostro, la extracción de características y el módulo de clasificación, la estructura del algoritmo se puede observar en la Figura 10.

En el enjambre de partículas con base en el árbol de decisión (BPSO) las clases se van ramifi- cando en niveles dependiendo de las características extraídas, de esta forma se llega al final de la rama que cumple en mayor porcentaje con los rasgos. Por otra parte la colonia de abejas (BA) crea un vecindario y las abejas empiezan a moverse buscando la mejor solución al patrón dado, en donde se resuelva un problema de minimización. Los resultados de la comparación con filtros combinados y con el clasificador difuso se muestran en la Tabla 5.

\begin{tabular}{|c|c|c|c|}
\hline \multicolumn{2}{|c|}{ TABLA 5. COMPARACIÓN DE RESULTADOS } \\
\hline \multirow{2}{*}{ Clasificador } & Filtros & \multicolumn{2}{|c|}{$\begin{array}{c}\text { \% de identificación con } \\
\text { UMIST (base de datos } \\
\text { libre de fotos) }\end{array}$} \\
\cline { 3 - 4 } FSVM & $\begin{array}{c}\text { Gabor Mag } \\
\text { +LDA }\end{array}$ & 96.11 & 95.18 \\
\hline BPSO & $\begin{array}{c}\text { Gabor Mag } \\
\text { +LDA }\end{array}$ & $\mathbf{9 7 . 2 2}$ & 95 \\
\hline BA & $\begin{array}{c}\text { Gabor Mag } \\
\text { +LDA }\end{array}$ & $\mathbf{9 7 . 2 2}$ & 96.3 \\
\hline FSVM & LDA & 94.44 & 92.22 \\
\hline BPSO & LDA & 95.55 & 94.81 \\
\hline BA & LDA & 96.67 & 94.26 \\
\hline
\end{tabular}

\section{Figura 10. Estructura del algoritmo de aprendizaje y comparación}

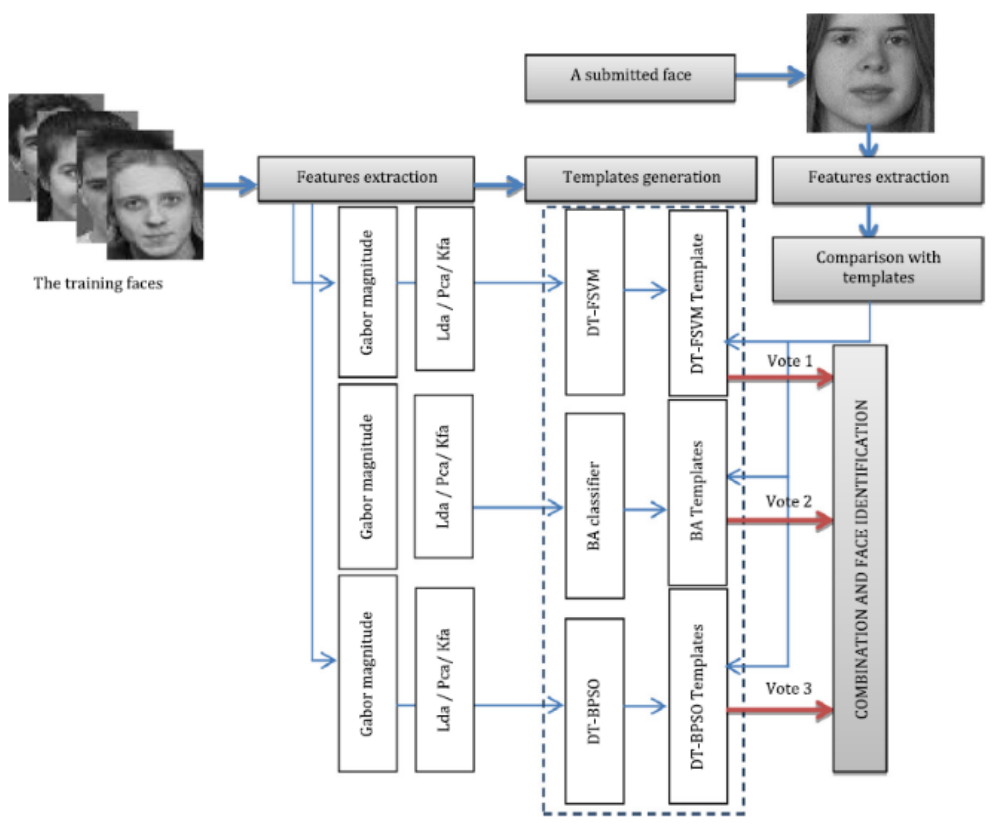




\subsection{Sistema inmune artificial (AIS)}

El sistema inmunológico de acuerdo con Schmidt, fuqaha, Gupta, y Kountanis (Schmidt et al., 2017) es el encargado de proteger a un organismo de elementos externos que puedan poner en riesgo la vida como por ejemplo bacterias, virus o paracitos, todos estos son conocidos como patógenos. El sistema tiene dos actividades básicas, el reconocimiento y eliminación de estos patógenos. De esta forma los AIS tratan de emular ese comportamiento para la solución de problemas utilizando el concepto de la producción de anticuerpos con base en información recopilada y guardada (Hatata \& Sedhom, 2017)(Kuo et al., 2016).

La interpretación de las imágenes médicas está sujeta a las propiedades específicas del instrumento que las toma y a la experiencia del profesional quien las diagnostica, por esto ha sido difícil crear un algoritmo estándar de reconocimiento de anomalías. La AIS se está utilizando recientemente en el procesamiento de imágenes con el propósito de hacer un reconocimiento más objetivo e independiente del profesional que hace el diagnóstico.

Entre los trabajos realizados se encuentra el de Magna, Casti, Jayaraman, Salmeri, Mencattini, Martinelli y Natale (Magna et al., 2016) que busca utilizando un modelo del sistema inmunológico artificial encontrar asimetrías en mamografías para poder detectar cáncer de seno, para lo cual entrenan el modelo con una base de datos patrón. Para el desarrollo del trabajo se usan alrededor de 200 muestras. Las cuales se procesan y segmentan para extraer 24 características, con los patrones previamente entrenados se clasifican los resultados en clases predefinidas. En la Figura 11 se puede ver la estructura propuesta.

Como resultado se obtiene un modelo con un acierto en la clasificación del 90\% usando la base de datos de imágenes DDSM mini-MIAS, lo cual muestra mejores resultados en comparación con trabajos que usan los mismos datos como el propuesto en (Magna et al., 2015) con 85\% y en (Casti et al., 2015) con $82 \%$.

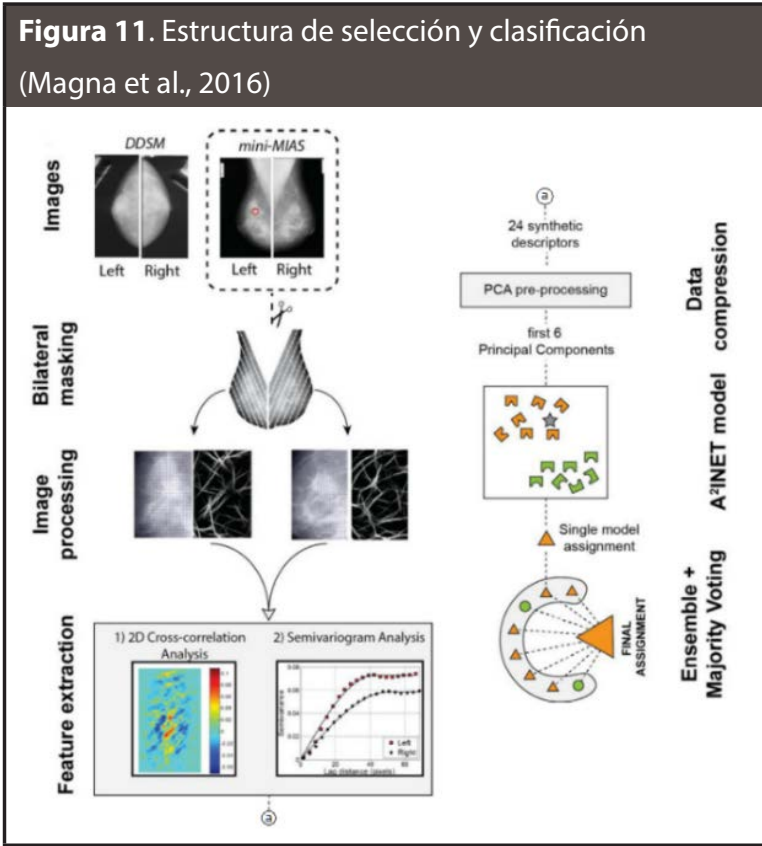

Otro caso de aplicación en el campo de la medicina es el presentado por los autores Gong, Tiantian, Lei Pei y Zixing (Gong et al., 2016) en donde se establece el problema de la estandarización de la lecturas de imágenes de resonancia magnética. En este trabajo se presenta el desarrollo de un algoritmo basado en la técnica de selección clonar del sistema inmunológico artificial modificado para mejorarlas imágenes. Los autores presentan como metodología de solución:

- Usar números reales para cifrar los anticuerpos de esta forma eliminar el cálculo de codificación en diferentes espacios numéricos.

- Limitar el campo de mutación en función de un radio entorno al clon original y su clon más lejano, evitando la dispersión de anticuerpos.

- Presentar un algoritmo en donde los anticuerpos forman vectores en un espacio de trabajo, a los cuales se les aplica una distribución gaussiana, uniforme y caótica para los procesos de mutación y de clonación, obligando al sistema a realizar una búsqueda global de soluciones. 
En la Figura 12 se observa el resultado en el filtrado y la correspondiente mejora de la imagen.

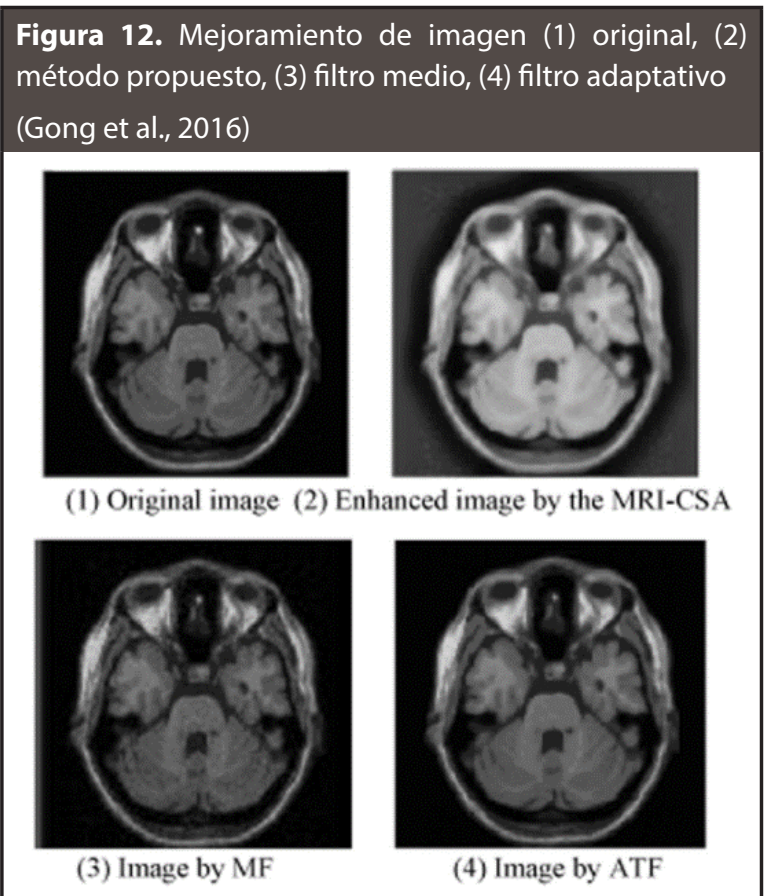

Los resultados presentan que el trabajo propuesto es más eficiente que los métodos de filtrado medio y filtro adaptativo, porque permite una mejor distribución del histograma de la imagen lo que permite detallar los elementos con mayor precisión.

\section{Aplicaciones IA en procesamiento digital de imágenes en pavimentos}

Las implementaciones de técnicas de inteligencia artificial ayudan a la solución de modelos complejos por eso se ha incrementado su uso en la ingeniería civil (Shafabakhsh et al., 2015). En el área de pavimentos se usan para realizar predicciones de comportamiento del material con un porcentaje de acierto elevado de acuerdo con Reza, Aghaeifar y Hossein(Reza et al., 2011), con lo cual se reducen los tiempos en pruebas de laboratorio ayudando a acelerar los análisis y diseño de las muestras (Shafabakhsh \& Tanakizadeh, 2015). En esta sección se revisan algunas aplicaciones del procesamiento digital de imágenes en pavimentos con la implementación de técnicas de inteligencia artificial. Así mismo se proponen posibles implementaciones en este campo.

\subsection{Aplicaciones de IA en imágenes de pavimentos}

El trabajo desarrollado en el área del procesamiento digital de imágenes en pavimentos utilizando técnicas de inteligencia artificial se ha basado en su mayoría en la detección de grietas o fisuras, un ejemplo de este es el trabajo desarrollado por Lijun Sun, Guobao Ning y Shengguang Tan (Sun et al., 2014) donde se propone un modelo de detección de grietas en diferentes estructuras de pavimentos para evaluar la condición de una vía utilizando una red neuronal con el algoritmo de back propagation. En la metodología del trabajo, primero se realiza el mejoramiento de la imagen, a partir de la corrección del histograma y después se segmentan las diferentes fisuras que serán clasificadas por la red. La red neuronal previamente entrenada define si la grieta es lineal o piel de cocodrilo. Después si la fisura es lineal, la misma red la clasifica entre longitudinal o transversal, determinando el ángulo de inclinación con respecto a la horizontal. La Tabla 6 muestra los resultados obtenidos con 40 imágenes.

\begin{tabular}{|c|c|}
\hline \multicolumn{2}{|c|}{ TABLA 6. PORCENTAJES DE ACIERTO } \\
\hline Tipo de grieta & Porcentaje de acierto (\%) \\
\hline Lineal & 97.5 \\
\hline Caimán & 87.5 \\
\hline Longitudinal & 88.0 \\
\hline Transversal & 100.0 \\
\hline
\end{tabular}

Los resultados según los autores en comparación con otros estudios mencionados en el trabajo tiene mejoras en la detección de más clases de grietas, es más simple y liviano disminuyendo el costo computacional, es fácilmente utilizable en la práctica y por último se tuvo en cuenta un mayor número de muestras en el entrenamiento de la red y la realización de las pruebas. 
En otro caso, Hyun Yoo y Young Kim (Yoo \& Kim 2016) presentan un algoritmo para el procesamiento digital de una imagen de una vía utilizando redes neuronales con el fin de segmentar la grietas adecuadamente quitando fisuras falsas provenientes de rayones en el suelo o elementos externos producto del tránsito normal. En la Figura $\mathbf{1 3}$ se puede ver el procesamiento digital que se realiza a la imagen, después de la adquisición se hace la binarización para después aplicarle un filtrado de ruido, seguido de operaciones morfológicas para tener una mejor definición. A la red neuronal ingresan las características propias de los pixeles negros de la imagen procesada como el área, distribución, intensidad, espesor de los vecindarios, entre otras. A la salida se obtendrá la segmentación de la grieta sin las fisuras falsas.

Los resultados se compararon con otro modelo realizado por los mismos autores utilizando un modelo de análisis de regresión logística que tuvo una precisión del $97.9 \%$ en la distinción entre fisura y ruido, mientras que el algoritmo con el modelo de red neuronal multicapa tiene un porcentaje del $99.4 \%$, de esta forma los autores concluyen que se deja un modelo confiable en la detección de grietas con diferenciación de ruido para un área de interés tan importante como el análisis del estado de vías, que en la mayoría de los casos se hace de forma manual y depende en gran parte del observador.

En la revisión realizada se observa que el procesamiento digital de imágenes con inteligencia artificial se usa en gran parte para la detección y modelado de grietas. Por otro lado, se realizan trabajos con métodos tradicionales como el de (Radopoulou \& Brilakis, 2015) en donde se busca detectar las reparaciones en las vías; en (Bessa et al., 2012)proponen por medio de técnicas de segmentación poder determinar las partículas fracturadas, puntos de contacto y orientación de los agregados de una muestra; en otra aplicación realizada en (Jiang et al., 2017) se busca determinar la distribución de los agregados en una foto para poder predecir características propias del comportamiento del material; de igual forma se trabaja en la detección de grietas y huecos como el modelo realizado en (Tedeschi \& Benedetto, 2017).

\section{Figura 13. Metodología del algoritmo ACSTM} (Yoo \& Kim, 2016)
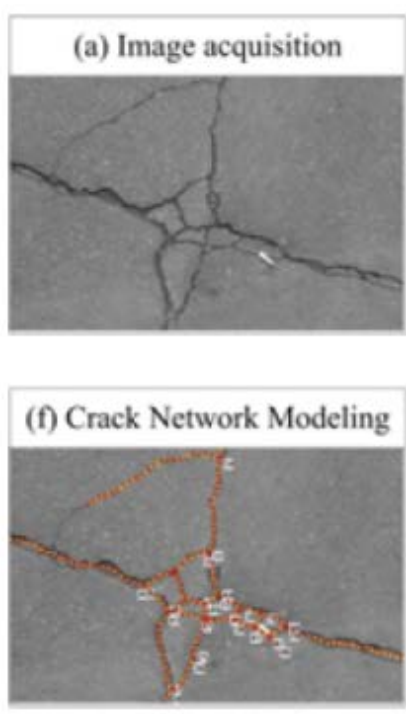

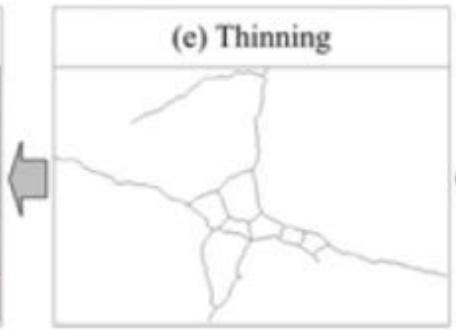

(b) Binarization

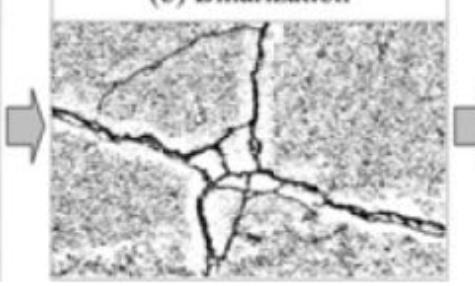

(e) Thinning (c) Noise Elimination

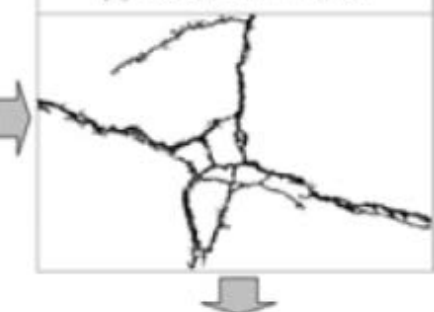

(d) Dilation

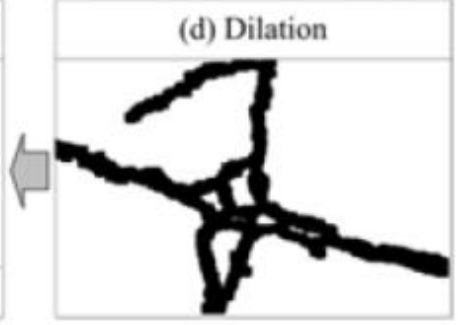




\subsection{Propuesta de trabajos futuros}

De la investigación bibliográfica se evidencia que el análisis de imágenes en pavimentos se utiliza en gran parte con métodos tradicionales de procesamiento digital y hasta hace poco se han empezado a implementar con técnicas de inteligencia artificial. A continuación se proponen algunas áreas de trabajo en los que la IA se podría utilizar:

a. Los algoritmos de detección de partículas, vacíos, grietas, contacto entre agregados y otras variables que establecen el comportamiento mecánico y dinámico de las capas de estructuras de pavimento, se podrían mejorar mediante la implementación de técnicas de inteligencia de enjambre o sistemas inmunes artificiales que son técnicas enfocadas en optimizar la solución de problemas buscando reducir el costo computacional de los mismos para crear códigos más eficientes.

b. Utilizar las redes neuronales de aprendizaje profundo para clasificar mezclas, grietas, tipo de agregado, entre otros, buscando predecir los comportamientos, estados o características propias de los materiales; en función del entrenamiento que se le puede realizar a este tipo de redes logrando altos porcentajes de acierto, debido a que la red se especializa en aprender rasgos característicos y extrapolarlos fácilmente usando el análisis espacial de imágenes.

c. El autoaprendizaje y la versatilidad de las técnicas de inteligencia artificial ante las variaciones permiten que se utilicen para realizar la segmentación y extracción de características de los pavimentos, optimizando recurso computacional, aumentando el grado de precisión y disminuyendo la sensibilidad de los métodos tradicionales ante perturbaciones externas.

d. Aplicar la inteligencia artificial en la caracterización de los materiales de las mezclas asfálticas en las escalas de meso, macro y micro estructura, con el objeto de evidenciar las características funcionales de las capas de rodadura de una estructura de pavimento.

\section{Conclusiones}

La revisión bibliográfica adelantada permite concluir lo siguiente acerca de la implementación de técnicas de inteligencia artificial en el estudio del área de pavimentos:

- Obtener las propiedades de las mezclas asfálticas requiere de equipos especializados y gran cantidad de tiempo de trabajo en laboratorios, pero la implementación de las diferentes técnicas de IA logran reducir costos y disminuir recursos elevados de equipos y tiempo.

- Se pueden establecer características de una mezcla asfáltica de manera rápida y precisa para el diseño, mantenimiento y construcción de vía por medio del mejoramiento y creación de algoritmos basados en inteligencia artificial y de todas las ventajas que estos proveen a un sistema.

- A partir de las aplicaciones revisadas en este trabajo se puede inferir que el procesamiento digital de imágenes es una de las herramientas más utilizadas en los campos de la ingeniería y medicina, la cual busca extraer el mayor número de elementos de la imagen para su caracterización, detección de patrones y procesos de selección y clasificación de objetos.

- El procesamiento digital de imágenes tiene desventajas claras con respecto a la sensibilidad y su limitación de procesamiento de datos, pero la inteligencia artificial ha solucionado el problema mediante la creación de sistemas robustos, con mayor grado de precisión y aplicados a la ingeniería. Las técnicas de inteligencia artificial son versátiles para la optimización de sistemas complejos al emular sistemas biológicos eficientes del mundo real. Por medio de la implementación de IA se reduce el costo computacional para encontrar soluciones optimizadas a problemas complejos gracias a que los algoritmos aprenden y se adaptan rápidamente.

- La inteligencia artificial será una herramienta económica, eficaz y eficiente que brindará soluciones en ingeniería, especialmente en el área de pavimentos con respecto a los métodos tradicionales de trabajo. 
Por otro lado, la revisión nos permite presentar un comparativo en la Tabla 7 de las diferentes técnicas de inteligencia artificial, donde se distinguen las ventajas y desventajas más importantes.

\section{TABLA 7. COMPARACIÓN DE LAS TÉCNICAS DE INTELIGENCIA ARTIFICIAL}

\begin{tabular}{|c|c|c|}
\hline Técnica IA & Ventajas & Desventajas \\
\hline $\begin{array}{l}\text { Sistemas difusos } \\
\text { (Abdullah \& } \\
\text { Abdolrazzagh- } \\
\text { nezhad 2014)(Lim } \\
\text { et al., 2015) }\end{array}$ & $\begin{array}{l}\text { - Su implementación al manejar un } \\
\text { esquema de lenguaje natural que simula } \\
\text { el del ser humano y la estandarización } \\
\text { de los modelos difusos permite que se } \\
\text { pueda aplicar de una forma práctica y } \\
\text { sencilla. } \\
\text { - Suavidad en la clasificación de sistemas } \\
\text { con grandes variaciones como las } \\
\text { imágenes, donde no se tener una } \\
\text { frontera definida por clase. }\end{array}$ & $\begin{array}{l}\text { Dificultad de la definición del problema de forma } \\
\text { precisa por medio de etiquetas y su porcentaje de } \\
\text { pertenencia, generalmente estas definiciones las } \\
\text { realizan personas desde su punto de vista lo que crea } \\
\text { un margen subjetivo. } \\
\text { - Por su funcionamiento no es aconsejable para } \\
\text { sistemas de alta precisión, debido a que el resultado } \\
\text { depende de un valor de pertenencia de funciones } \\
\text { parametrizadas bajo un sistema lingüístico y no } \\
\text { numérico }\end{array}$ \\
\hline $\begin{array}{l}\text { Red neuronal } \\
\text { MLP } \\
\text { (Cristea et al. } \\
\text { 2016)(Jani et al., } \\
\text { 2017) }\end{array}$ & $\begin{array}{l}\text { - Aprendizaje rápido con gran porcentaje } \\
\text { de acierto } \\
\text { - Capacidad de procesamiento en paralelo } \\
\text { lo que lo convierte en un sistema muy } \\
\text { útil en sistemas de respuesta rápida } \\
\text { - La implementación de una red neuronal } \\
\text { MLP es simple en comparación con otras } \\
\text { técnicas IA o incluso otros tipos de redes } \\
\text { neuronales }\end{array}$ & $\begin{array}{l}\text { - Necesitan un reentrenamiento periódico para no } \\
\text { perder precisión, ante cambios normales que un } \\
\text { sistema presenta en el tiempo } \\
\text { - Entre más grande el rango dinámico de trabajo más } \\
\text { datos representativos son necesarios para definir las } \\
\text { diferentes pendientes de separación. }\end{array}$ \\
\hline $\begin{array}{l}\text { Red neuronal } \\
\text { convolucional } \\
\text { (Galdámez et al., } \\
\text { 2017)(Cao et al., } \\
\text { 2017) }\end{array}$ & $\begin{array}{l}\text { - Red especializada en el trabajo con } \\
\text { imágenes por su funcionamiento } \\
\text { en 2D que permite la extracción de } \\
\text { características globales de la foto por } \\
\text { medio de las diferentes matrices de filtros. } \\
\text { - Robustez de la identificación ante } \\
\text { variaciones en las imágenes por la } \\
\text { implementación de algoritmos de Deep } \\
\text { Learning que permite a la red aprender } \\
\text { múltiples niveles de representación. }\end{array}$ & $\begin{array}{l}\text { - Tiempos de entrenamiento largos } \\
\text { - La calidad de la identificación depende de la } \\
\text { extensión de la base de imágenes que se use para } \\
\text { entrenamiento } \\
\text { - Sistema de alto costo computacional por su trabajo } \\
\text { con matrices y convoluciones entre ellas. }\end{array}$ \\
\hline $\begin{array}{l}\text { Inteligencia de } \\
\text { enjambre } \\
\text { (Colonia de } \\
\text { abejas) } \\
\text { (Cui et al. 2017) } \\
\text { (Banitalebi et al., } \\
\text { 2015) }\end{array}$ & $\begin{array}{l}\text { - Convergencia rápida a la solución de los } \\
\text { sistemas con gran flexibilidad } \\
\text { - Este tipo de técnica utiliza pocos } \\
\text { parámetros de configuración en } \\
\text { comparación con las otras técnicas } \\
\text { mencionadas. }\end{array}$ & $\begin{array}{l}\text { - En ocasiones existen soluciones mejores en la solución } \\
\text { local a la cual el algoritmo converge, lo que hace } \\
\text { necesario un algoritmo externo de búsqueda global } \\
\text { dentro de esa región para enconar la mejor solución. } \\
\text { - Presenta en situaciones convergencia prematura a una } \\
\text { solución, esto se debe una mala configuración de la } \\
\text { estructura de búsqueda que sesga el mejor resultado. }\end{array}$ \\
\hline $\begin{array}{l}\text { Sistema inmune } \\
\text { artificial } \\
\text { (Bayar et al., } \\
\text { 2015)(Costa et al., } \\
\text { 2017) }\end{array}$ & $\begin{array}{l}\text { - Alta capacidad de exploración de } \\
\text { soluciones, para una mejor optimización } \\
\text { de tareas } \\
\text { - Posee un autoaprendizaje estructurado, } \\
\text { profundo y simple en comparación con } \\
\text { otras técnicas de IA las cuales no tienen } \\
\text { la capacidad de aprender de forma } \\
\text { autónoma. }\end{array}$ & $\begin{array}{l}\text { - Requiere un alto nivel de desarrollo en su } \\
\text { programación inicial para estructurar sus capas y } \\
\text { funcionamiento } \\
\text { - Su mayor fortaleza la saca de procesos de } \\
\text { aleatoriedad que en principio le resta propiedades de } \\
\text { robustez a su implementación. }\end{array}$ \\
\hline
\end{tabular}


Las técnicas de inteligencia artificial de acuerdo con la tabla anterior tienen ventajas muy específicas en procesos de optimización, recursividad, velocidad de respuesta, costo computacional, flexibilidad, entre otras. Cada una se enfoca en métodos de trabajo diferentes que pueden ayudar en la solución de diversos problemas, pero así como tienen grandes ventajas también poseen desventajas en su funcionamiento e implementación. Para mejorar esto en años recientes se han integrado las diferentes técnicas para poder trabajar con modelos híbridos y disminuir las dificultades que estos presentan individualmente. De esta forma es posible abordar nuevos campos de estudio y análisis como el procesamiento digital de imágenes, un campo joven con grandes potenciales en el área de pavimentos.

\section{Agradecimientos}

Los autores agradecen a la Vicerrectoría de investigaciones de la Universidad Militar Nueva Granada, en especial por el financiamiento del proyecto de investigación de alto Impacto IMP-ING-2132.

\section{Referencias}

Abdullah, S. \& Abdolrazzagh-nezhad, M., 2014. Fuzzy job-shop scheduling problems : A review. Information Sciences, 278, pp.380-407. Available at: http:// dx.doi.org/10.1016/j.ins.2014.03.060.

Ali, M. et al., 2015. An image watermarking scheme in wavelet domain with optimized compensation of singular value decomposition via artificial bee colony. Information Sciences, 301, pp.44-60. Available at: http://dx.doi.org/10.1016/j.ins.2014.12.042.

Apostolidis, G.K. \& Hadjileontiadis, L.J., 2017. Swarm decomposition: A novel signal analysis using swarm intelligence. Signal Processing journal, 132, pp.40-50.

Arjmandzadeh, Z., Safi, M. \& Nazemi, A., 2017. A new neural network model for solving random interval linear programming problems. Neural Networks, 89, pp.11-18.

Athertya, J.S. \& Saravana Kumar, G., 2016. Automatic segmentation of vertebral contours from CT images using fuzzy corners. Computers in Biology and Medicine, 72, pp.75-89.

Babashamsi, P. et al., 2016. Evaluation of pavement life cycle cost analysis: Review and analysis. International Journal of Pavement Research and Technology, 9, pp.241-254. Available at: http://dx.doi. org/10.1016/j.ijprt.2016.08.004.

Banitalebi, A. et al., 2015. Enhanced compact artificial bee colony. INFORMATION SCIENCES, 298, pp.491511. Available at: http://dx.doi.org/10.1016/j. ins.2014.12.015.

Bayar, N. et al., 2015. Fault detection, diagnosis and recovery using Arti fi cial Immune Systems : A review. Engineering Applications of Artificial Intelligence, 46, pp.43-57.

Berrocal, C.G.. et al., 2016. Characterisation of bending cracks in R/FRC using image analysis. submitted to: Materials and Structures, 90, pp.104-116.

Bessa, I.S., Castelo Branco, V.T.F. \& Soares, J.B., 2012. Evaluation of different digital image processing software for aggregates and hot mix asphalt characterizations. Construction and Building Materials, 37, pp.370-378.

Bianconi, F. et al., 2015. Grain-size assessment of fine and coarse aggregates through bipolar area morphology. Machine Vision and Applications, 26(6), pp.775-789. Available at: http://link.springer.com/10.1007/ s00138-015-0692-z.

Bose, A. \& Mali, K., 2016. Fuzzy-based artificial bee colony optimization for gray image segmentation. Signal, Image and Video Processing, 10, pp.1089-1096.

Bouchet, A. et al., 2016. Fuzzy mathematical morphology for color images defined by fuzzy preference relations. Pattern Recognition, 60, pp.720-733.

Cao, W. et al., 2017. A review on neural networks with random weights. Neurocomputing, 0, pp.1-10.

Casti, P. et al., 2015. Analysis of structural similarity in mammograms for detection of bilateral asymmetry. IEEE Trans. Med. Imaging, 34(2), pp.662-671.

Cordeiro, F.R., Santos, W.P. \& Silva-Filho, A.G., 2016. A semi-supervised fuzzy GrowCut algorithm to segment and classify regions of interest of mammographic images. Expert Systems with Applications, 65, pp.116-126.

Costa, G., Matos, W. \& Martinez, R., 2017. Artificial immune systems applied to fault detection and isolation : A brief review of immune response-based ap- 
proaches and a case study. Applied Soft Computing Journal, 57, pp.118-131. Available at: http://dx.doi. org/10.1016/j.asoc.2017.03.031.

Cristea, V., Leblebici, Y. \& Almási, A., 2016. Neurocomputing Review of advances in neural networks : Neural design technology stack. Neurocomputing, 174, pp.31-41.

Cui, L. et al., 2017. A novel artificial bee colony algorithm with an adaptive population size for numerical function optimization. Information Sciences, 414, pp.53-67.

Espinoza, K. et al., 2016. Combination of image processing and artificial neural networks as a novel approach for the identification of Bemisia tabaci and Frankliniella occidentalis on sticky traps in greenhouse agriculture. Computers and Electronics in Agriculture, 127, pp.495-505.

Ferrari, A., Lombardi, S. \& Signoroni, A., 2017. Bacterial colony counting with Convolutional Neural Networks in Digital Microbiology Imaging. Pattern Recognition journal, 61, pp.629-640.

Galdámez, P.L., Raveane, W. \& Arrieta, A.G., 2017. A brief review of the ear recognition process using deep neural networks. Journal of Applied Logic, 24, pp.6270. Available at: http://dx.doi.org/10.1016/j. jal.2016.11.014.

Gong, T. et al., 2016. Magnetic resonance imaging-clonal selection algorithm: An intelligent adaptive enhancement of brain image with an improved immune algorithm. Engineering Applications of Artificial Intelligence, (October).

Han, J. et al., 2016. 2D image analysis method for evaluating coarse aggregate characteristic and distribution in concrete. Construction and Building Materials, 127, pp.30-42.

Hatata, A.Y. \& Sedhom, B.E., 2017. Proposed Sandia frequency shift for anti-islanding detection method based on artificial immune system. Alexandria Engineering Journal.

Hekayati, J. \& Rahimpour, M.R., 2017. Estimation of the saturation pressure of pure ionic liquids using MLP arti fi cial neural networks and the revised isofugacity criterion. Journal of Molecular Liquids journal, 230, pp.85-95.

Helena, G., Miranda, B. \& Cezar, J., 2015. Computer-aided diagnosis system based on fuzzy logic for breast cancer categorization. , 64, pp.334-346.
Hu, L. et al., 2016. Effect of three-dimensional macrotexture characteristics on dynamic frictional coefficient of asphalt pavement surface. Construction and Building Materials, 126, pp.720-729.

Huang, C., Li, H. \& Li, W., 2017. Store classification using TextExemplar-Similarity and Hypotheses- Weighted-CNN. J. Vis. Commun. Image R. journal, 44, pp.21-28.

Hugo, V. et al., 2009. Evaluation of multilayer perceptron and self-organizing map neural network topologies applied on microstructure segmentation from metallographic images. NDT \& E International, 42, pp.644-651.

Islam, S. et al., 2014. Solid waste bin detection and classification using Dynamic Time Warping and MLP classifier. Waste Management, 34, pp.281-290.

Jani, D.B., Mishra, M. \& Sahoo, P.K., 2017. Application of arti fi cial neural network for predicting performance of solid desiccant cooling systems - A review. Renewable and Sustainable Energy Reviews, 80(November 2016), pp.352-366. Available at: http://dx.doi. org/10.1016/j.rser.2017.05.169.

Jiang, J. et al., 2017. Effect of the contact structure characteristics on rutting performance in asphalt mixtures using 2D imaging analysis. Construction and Building Materials, 136, pp.426-435.

Knabben, R.M. et al., 2016. Evaluation of sound absorption capacity of asphalt mixtures. Applied Acoustics, 114, pp.266-274. Available at: http://dx.doi. org/10.1016/j.apacoust.2016.08.008.

Kumar, D. \& Mishra, K.K., 2017. Portfolio optimization using novel co-variance guided Artificial Bee Colony algorithm. Swarm and Evolutionary Computation journal, 33(April 2016), pp.119-130.

Kuo, R.., Tseng, Y.. \& Yao Chen, Z., 2016. Integration of fuzzy neural network and artificial immune system-based back-propagation neural network for sales forecasting using qualitative and quantitative data. Journal of Intelligent Manufacturing, 27, pp.1191-1207.

Li, B. et al., 2016. Optik Image retrieval via balance-evolution artificial bee colony algorithm and lateral inhibition. , 127, pp.11775-11785.

Li, Q. et al., 2011. FoSA: F* Seed-growing Approach for crack-line detection from pavement images. Image and Vision Computing, 29(12), pp.861-872.

Lim, C.H., Vats, E. \& Seng, C., 2015. Fuzzy human motion analysis : A review. Pattern Recognition journal, 48, pp.1773-1796. 
Magna, G. et al., 2015. Adaptive classification model based on artificial immune system for breast cancer detection. Proceedings of the Eighteenth AISEM Annual Conference.

Magna, G. et al., 2016. Identification of mammography anomalies for breast cancer detection by an ensemble of classification models based on artificial immune system. Knowle dge-Based Systems, 101, pp.60-70.

Mashaly, A.F. \& Alazba, A.A., 2016. MLP and MLR models for instantaneous thermal efficiency prediction of solar still under hyper-arid environment. Computers and Electronics in Agriculture, 122, pp.146-155.

Mavrovouniotis, M., Li, C. \& Yang, S., 2017. A survey of swarm intelligence for dynamic optimization: Algorithms and applications. Swarm and Evolutionary Computation journal, 33(January), pp.1-17.

Mejía, M. \& Alzate, M., 2015. Clasificación automática de formas patológicas de eritrocitos humanos Automatic classification of pathological shapes in human erythrocytes. Revista Ingeniería, 21(1), pp.31-48.

Michalska-Po??oga, I. et al., 2016. Towards the usage of image analysis technique to measure particles size and composition in wood-polymer composites. Industrial Crops and Products, 92, pp.149-156.

Mollajan, A., Ghiasi-Freez, J. \& Memarian, H., 2016. Improving pore type identification from thin section images using an integrated fuzzy fusion of multiple classifiers. Journal of Natural Gas Science and Engineering, 31, pp.396-404.

Nebti, S. \& Boukerram, A., 2017. Swarm intelligence inspired classi fi ers for facial recognition. Swarm and Evolutionary Computation, 32, pp.150-166.

Ngan, S., 2017. A unified representation of intuitionistic fuzzy sets, hesitant fuzzy sets and generalized hesitant fuzzy sets based on their u-maps., 69, pp.257276.

Priya, E. \& Srinivasan, S., 2016. ScienceDirect Automated object and image level classification of TB images using support vector neural network classifier. pp.1-9.

Radopoulou, S.C. \& Brilakis, I., 2015. Patch detection for pavement assessment. Automation in Construction, 53, pp.95-104.

Reza, M. et al., 2011. Permanent deformation analysis of asphalt mixtures using soft computing techniques. Expert Systems with Applications, 38, pp.6081-6100.
Schmidt, B. et al., 2017. Optimizing an artificial immune system algorithm in support of flow-Based internet traffic classification. Applied Soft Computing j, 54, pp.1-22.

Sebari, I. \& He, D., 2013. Automatic fuzzy object-based analysis of VHSR images for urban objects extraction. ISPRS Journal of Photogrammetry and Remote Sensing, 79, pp.171-184.

Sebari \& He, 2009. Approach to nonparametric cooperative multiband segmentation with adaptive threshold. Applied Optics, 20, pp.3967-3978.

Shafabakhsh, G. \& Tanakizadeh, A., 2015. Investigation of loading features effects on resilient modulus of asphalt mixtures using Adaptive Neuro-Fuzzy Inference System. Construction and Building Materials, 76, pp.256-263.

Shafabakhsh, G.H., Ani, O.J. \& Talebsafa, M., 2015. Artificial neural network modeling ( ANN) for predicting rutting performance of nano-modified hot-mix asphalt mixtures containing steel slag aggregates. Construction and Building Materials journal, 85, pp.136-143.

Shang, R. et al., 2014. Engineering Applications of Arti fi cial Intelligence Change detection in SAR images by arti fi cial immune multi-objective clustering. Engineering Applications of Artificial Intelligence, 31, pp.1-15. Available at: http://dx.doi.org/10.1016/j. engappai.2014.02.004.

Sun, L., Ning, G. \& Tan, S., 2014. AUTOMATIC PAVEMENT CRACK RECOGNITION BASED ON BP NEURAL NETWORK. Swarm Intelligence in Transportation Engineering, 26(1), pp.11-22.

Tan, J.H. et al., 2017. Segmentation of optic disc, fovea and retinal vasculature using a single convolutional neural network. Journal of Computational Science.

Tedeschi, A. \& Benedetto, F., 2017. A real-time automatic pavement crack and pothole recognition system for mobile Android-based devices. Advanced Engineering Informatics, 32, pp.11-25.

Yangyan, L. et al., 2015. Joint Embeddings of Shapes and Images via CNN Image Purification. ACM Transactions on Graphics, 34(6), pp.1-12.

Yoo, H. \& Kim, Y., 2016. Development of a Crack Recognition Algorithm from Non-routed Pavement Images using Artificial Neural Network and Binary Logistic Regression. KSCE Journal of Civil Engineering, 20, pp.1151-1162. 
Yu, X. et al., 2016. Infrared Physics \& Technology Target extraction of banded blurred infrared images by immune dynamical algorithm with two-dimensional minimum distance immune field. , 77, pp.94-99.

Zhang, G. et al., 2017. SIFT Matching with CNN Evidences for Particular Object Retrieval. Neurocomputing, 0, pp.1-11.

Zhang, W. et al., 2016. Learning structure of stereoscopic image for no-reference quality assessment with convolutional neural network. Pattern Recognition journal, 59, pp.176-187. 